\title{
Conservantes florais comerciais nas soluções de manutenção de hastes florais de gérbera de corte
}

\author{
Commercial floral preservative in solutions in the maintenance of gerbera floral stalks
}

\author{
Fernanda Schmitt ${ }^{\mathrm{I}}$ Marília Milani $^{{ }^{*}}$ Valmir Duarte ${ }^{\mathrm{II}}$ Gilmar Schafer ${ }^{\mathrm{III}}$ \\ Renar João Bender ${ }^{\text {III }}$
}

\section{RESUMO}

As flores de corte são produtos altamente pereciveis e sua vida pós-colheita deve ser prolongada ao máximo para garantir a fidelidade dos consumidores. Uma possivel medida para ampliar o período pós-colheita é a adição de fontes exógenas como biocidas, açúcares e substâncias acidificantes, compostos presentes nos conservantes florais comerciais. Nesse sentido, objetivou-se avaliar a eficácia do uso de conservantes florais na longevidade pós-colheita e na redução do número de bactérias em hastes florais de gérbera de corte. Seis hastes florais por unidade experimental de gérberas 'Essandre', colhidas em produtor comercial, foram condicionadas em frascos de vidro com $1 L$ das seguintes soluções: $T 1$ - água destilada (tratamento testemunha); T2-1,0\% (v/v) Flower $^{\circledR} ;$ T3-1,5\% (v/v) Flower ${ }^{\circledR} ;$ T4-1,0\% (v/v) Flower Plus ${ }^{\circledR} ;$ T51,5\% (v/v) Flower Plus ${ }^{\circledast}$; e T6-1 tablete de Florissant 500 $0^{\circ}$. Ao final de 7 dias, observou-se o conteúdo de carboidratos totais $e$, ao final do experimento: a longevidade; a massa fresca relativa; e a absorção de solução. Nas soluções de vaso, durante o período experimental, avaliou-se o pH. A contagem bacteriana, nas hastes florais, foi realizada com os tratamentos: T1 - água destilada (tratamento testemunha); T2-0,75\% (v/v) Flower ${ }^{\circledR}$; T3-1,5\% $(v / v)$ Flower $^{\circledR}$. Os conservantes florais testados não aumentam a longevidade pós-colheita de hastes florais de gérbera de corte. O uso de conservante floral reduz o número de bactérias em hastes florais de gérbera de corte.

Palavras-chave: Gerbera jamesonii, pós-colheita, vida em vaso, soluções de manutenção, floricultura.

\section{ABSTRACT}

Cut flowers are highly perishable products and its shelf-life should be prolonged to the maximum to ensure the fidelity of consumers. A measure to assist vase life lengthening might most likely derives from the addition of exogenous sources of biocides, carbohydrates and acidifying substances compounds present in commercial floral preservatives. The objective of this study was to evaluate the efficacy of floral preservatives on postharvest longevity, and reducing the number of bacteria in gerbera cut flowers. Six cv. 'Essandre' gerbera flower stalks as experimental unit were harvested at a commercial cut flower producer and placed in glass jars with $1 L$ of these solutions: T1 - distilled water (control treatment); T2-1,0\% (v/v) Flower ${ }^{\circledR}$; T31,5\% (v/v) Flower ${ }^{\circledR}$; T4-1,0\% (v/v) Flower Plus ${ }^{\circledR}$; T5-1,5\% (v/v) Flower Plus ${ }^{\circledR}$ and T6 - one tablet Florissant 500 ${ }^{\circ}$. The following variables were evaluated at the end of shelf life of the flower stalks: contents of storage substances, longevity, relative fresh weight and solution uptake. The pH of vase solutions was determined along the evaluation period. Bacterial counts were performed from solutions of the following treatments: T1 - distilled water (control treatment); T2-0,75\% (v/v) Flower ${ }^{\circledR}$; and T3-1,5\% (v/v) Flower ${ }^{\circledR}$. The floral preservatives tested did not increase the postharvest longevity of gerbera cut flowers. The use of floral preservative reduces the number of bacteria in gerbera cut flowers.

Key words: Gerbera jamesonii, postharvest, vase life, maintenance solutions, floriculture.

\section{INTRODUÇÃO}

O agronegócio da floricultura no Brasil está em expansão, devido o ganho em qualidade, em competitividade e por ramificar-se nos diversos estados. Desse modo, consolida-se como importante atividade econômica em todo o País. O potencial de expansão da atividade, voltada tanto para o mercado interno como para exportação, é enorme e

IPrograma de Pós-graduação em Fitotecnia, Faculdade de Agronomia (FAGRO), Universidade Federal do Rio Grande do Sul (UFRGS), Av. Bento Gonçalves, 7712, Bairro Agronomia, 91540-000, Porto Alegre, RS, Brasil. E-mail: mariliakmilani@ gmail.com. *Autor para correspondência.

IDepartamento de Fitossanidade, FAGRO, UFRGS, Porto Alegre, RS, Brasil.

IIIDepartamento de Horticultura e Silvicultura, FAGRO, UFRGS, Porto Alegre, RS, Brasil. 
oferece oportunidades promissoras (BUAINAIN \& BATALHA, 2007).

Dentre as flores cultivadas, a gérbera (Gerbera jamesonii) ocupa posição de destaque, no que diz respeito à comercialização e valor econômico para o setor de flores de corte, pertencente ao grupo das principais espécies enviadas ao exterior (JUNQUEIRA \& PEETZ, 2009). A espécie é uma das mais importantes culturas no comércio mundial de flores de corte e de vaso, estando em quinto lugar no ranking (BHATIAA et al., 2009).

A durabilidade pós-colheita é um dos principais aspectos a serem observados na produção de flores para corte e constitui um pré-requisito para a qualidade do produto e para o sucesso da comercialização (CASTRO et al., 2007). Um dos fatores que determina a longevidade das flores cortadas é a quantidade de água transportada pela haste. O principal obstáculo ao fluxo de água são os bloqueios bacterianos nos tecidos xilemáticos junto ao local de corte das hastes (MERCURIO, 2002). A razão pela qual as bactérias se multiplicam na base das hastes assim que estas são dispostas em água é facilmente entendida, pois as células cortadas da base liberam carboidratos, aminoácidos, proteínas, entre outros materiais que são alimentos adequados para as centenas de bactérias presentes na superfície das plantas (REID \& DODGE, 1997).

A vida de vaso das flores pode ser aumentada pelo adequado manuseio, utilizandose conservantes florais, os quais geralmente são constituídos por carboidratos, germicidas, inibidores de etileno, reguladores de crescimento e alguns compostos minerais (ALMEIDA et al., 2008). Os produtos conservantes podem ser benéficos para algumas espécies e para outras não. Assim, é importante o entendimento do metabolismo de conservação pós-colheita através da realização de experimentos, para avaliar se o conservante floral é ou não adequado para determinada espécie antes de recomendá-lo em grande escala.

Portanto, objetivou-se, no presente trabalho, avaliar a eficácia do uso de conservantes florais na longevidade pós-colheita, e na redução do número de bactérias em hastes florais de gérbera de corte.

\section{MATERIAL E MÉTODOS}

O experimento foi conduzido utilizando hastes de gérbera da cultivar 'Essandre', cultivadas em ambiente protegido e obtidas da Empresa Florist, estabelecida no município de Dois Irmãos, Rio Grande do Sul (RS), latitude: 29³4'S, longitude: $51^{\circ} 05^{\prime} \mathrm{O}$ e altitude: $166 \mathrm{~m}$. As hastes foram colhidas, acondicionadas em papel jornal e transportadas em veículo fechado, sem refrigeração, ao Laboratório de Pós-colheita do Departamento de Horticultura e Silvicultura da Faculdade de Agronomia da Universidade Federal do Rio Grande do Sul (UFRGS), distante aproximadamente $55 \mathrm{~km}$ do local de produção.

No laboratório, as hastes foram padronizadas para $40 \mathrm{~cm}$ de comprimento. Em seguida, foram distribuídas para vasos com capacidade de 3,3L, contando $1 \mathrm{~L}$ das seguintes soluções avaliadas: T1 - água destilada (tratamento testemunha); T2-1\% (v/v) Flower ${ }^{\circledR}$ (composição: carboidratos, vitaminas, antioxidantes, acidulantes, bactericida, algicida, antichampignon, sais inorgânicos; fabricante Ecoplanet $\left.{ }^{\circledR}\right)$; T3-1,5\% (v/v) Flower ${ }^{\circledR}$ (fabricante Ecoplanet $\left.{ }^{\circledR}\right)$; T4$1,0 \%$ (v/v) Flower Plus ${ }^{\circledR}$ (composição: carboidratos, vitaminas, antioxidante, acidulante, bactericida, sais inorgânicos e anti-etileno; fabricante Ecoplanet $\left.^{\circledR}\right)$; T5-1,5\% (v/v) Flower Plus ${ }^{\circledR}$ (fabricante Ecoplanet ${ }^{\circledR}$ ) e T6-1 tablete por litro de Florissant $500^{\circ}$ (composição: cloramina T de liberação lenta; fabricante Roskam ${ }^{\odot}$ ).

Ao final de sete dias, em temperatura ambiente, observou-se o conteúdo de carboidratos totais e ao final do experimento: a longevidade; a massa fresca relativa; e a absorção de solução. O fim do experimento foi variável em função do tratamento aplicado. Nas soluções de vaso, durante o período experimental, avaliou-se o $\mathrm{pH}$.

Para determinação do conteúdo de carboidratos totais, foi demarcada uma haste floral por unidade experimental e os tratamentos testados foram os seis já descritos acima, além do tratamento 'testemunha branca', caracterizado pelo tecido retirado no dia da colheita, isto é, tempo zero. As hastes demarcadas foram segmentadas para secagem em estufa a $65^{\circ} \mathrm{C}$ até massa constante. Após a completa secagem, o material foi triturado em moinho de motor circular até passar por peneira de 30 mesh. Sacos de tecido especial para filtragem de alimentos foram identificados e pesados, receberam aproximadamente $1 \mathrm{~g}$ da amostra e foram novamente pesados. A determinação da quantidade de reservas foi feita através do método da digestão ácida, segundo adaptações do método de Priestley, descrito por SOUZA (1990).

A contagem bacteriana foi realizada após as hastes florais ficarem por sete dias, nas seguintes soluções de vaso: T1 - água destilada (tratamento testemunha); T2-0,75\% (v/v) Flower ${ }^{\circledR}$ (fabricante Ecoplanet $\left.^{\circledR}\right) ; \quad$ T3-1,5\% (v/v) Flower ${ }^{\circledR} \quad$ (fabricante Ecoplanet $^{\circledR}$ ). 
A temperatura média registrada durante o período experimental foi de $20^{\circ} \mathrm{C}$ e a umidade relativa igual a $66,5 \%$, medidas através de psicrômetro de bulbo úmido e seco.

A avaliação de longevidade das hastes foi feita visualmente. Foi considerado o número de dias após a colheita em que as hastes permaneciam com bom aspecto visual levando-se em conta os seguintes critérios: quebra das hastes, murchamento, deformação ou mudança de cor nas pétalas e curvatura acentuada da haste.

Para obtenção da massa fresca relativa, utilizou-se a massa das hastes durante o período experimental, através do cálculo com a fórmula: $\operatorname{MFR}(\%)=($ Mt $\times 100) / M t=0$, na qual: $M t=$ massa da haste $(\mathrm{g})$ no $\mathrm{t}=$ dias após a colheita; $\mathrm{Mt}=0=$ massa da haste $(\mathrm{g})$ no dia da colheita.

A absorção de solução $\left(\mathrm{mL} \operatorname{dia}^{-1} \mathrm{~g}^{-1} \mathrm{de}\right.$ massa fresca $)=\left(\mathrm{S}_{\mathrm{t}-1}-\mathrm{S}_{\mathrm{t}}\right) / \mathrm{M}_{\mathrm{t}=0}$, na qual: $\mathrm{S}_{\mathrm{t}}=$ peso da solução $(\mathrm{g})$ no $\mathrm{t}=$ dias após a colheita; $\mathrm{S}_{\mathrm{t}-1}=$ peso da solução $(\mathrm{g})$ no dia anterior e $\mathrm{M}_{\mathrm{t}=0}=$ massa da haste no dia da colheita (adaptado de ANTES et al., 2009).

$\mathrm{O} \mathrm{pH}$ das soluções de tratamento foi avaliado durante o período do experimento, com auxílio de um potenciômetro (Digimed, modelo DM-20), imergindo o eletrodo em cada unidade experimental. Após cada leitura, o eletrodo foi lavado com água destilada para não haver contaminação cruzada.

Para a contagem bacteriana, cortou-se um segmento de cinco $\mathrm{cm}$ a partir da base de cada haste floral, desprezando-se o primeiro centímetro. Segmentos de cerca de dois $\mathrm{mm}$ foram pesados e desinfestados por um minuto em etanol $70 \%(\mathrm{v} / \mathrm{v})$, seguido de um minuto em hipoclorito de sódio a $1 \%$ (v/v) e enxágue em água destilada esterilizada. $\mathrm{O}$ segmento desinfestado foi transferido para $1 \mathrm{~mL}$ de água destilada esterilizada (ADE) em tubo Eppendorf de $2 \mathrm{~mL}$ de volume, agitando-se por 10 segundos. Pipetou-se $10 \mu \mathrm{L}$ da suspensão para transferir para o meio nutriente Agar (NA) em placa de Petri. Após $48 \mathrm{~h}$ em câmara de crescimento a $28^{\circ} \mathrm{C}$ no escuro, procedeu-se à observação e contagem de colônias bacterianas nas placas.

O delineamento experimental utilizado foi o inteiramente casualizado, com três repetições e seis hastes florais por unidade experimental. Os dados foram submetidos à análise de variância, e as médias foram comparadas pelo teste Duncan, em nível de $5 \%$ de probabilidade de erro. Os dados envolvendo contagens de bactérias, em função de não satisfazerem os testes de normalidade, foram analisados após a transformação de dados $(\sqrt{ } \mathrm{x}+0,5)$, recomendável para resultados de contagens, em que zeros estão envolvidos.

\section{RESULTADOS E DISCUSSÃO}

A longevidade das hastes variou, em média, de nove a doze dias, diferindo estatisticamente em resposta aos diferentes tratamentos. A maior vida em vaso (doze dias) foi obtida nas hastes condicionadas em solução contendo um tablete de Florissant $500^{\circ}$. No entanto, não diferiram deste os tratamentos: testemunha; $1 \%$ (v/v) Flower $^{\circledR}$ e 1\% (v/v) FlowerPlus ${ }^{\circledR}$. O principal composto bactericida de Florissant $500^{\circ}$ é o cloro, que possui efeito germicida, combatendo bactérias e outros microrganismos nocivos às flores cortadas. Resultado semelhante, encontrado por DURIGAN (2009), que verificou que os tratamentos contendo cloro mantiveram a boa qualidade das flores por um período maior, quando comparado às soluções de ácido cítrico e água destilada.

Em relação ao uso de conservante floral, ANTES et al. (2009) testaram Flower ${ }^{\circledR}$ em hastes de gérbera de corte, cv. 'Patrizia', e não encontraram diferença entre as concentrações utilizadas - $0,75 \%$, $1 \%$ e $1,5 \%(\mathrm{v} / \mathrm{v})$, evidenciando que a longevidade em hastes de gérbera de corte é variável, conforme a cultivar utilizada. Resultado semelhante obtido por CURTI et al. (2009), que, ao testarem o mesmo produto, não encontraram eficiência na conservação de hastes de girassol (Hellianthus annuus) de corte, e o efeito foi negativo, acelerando a senescência na proporção em que as concentrações foram aumentadas; e por ALMEIDA et al. (2009), que, ao trabalharem com rosas de corte, não detectaram diferenças significativas entre as soluções contendo os produtos comerciais, entre eles Flower ${ }^{\circledR}$.

Estes resultados diferiram dos encontrados por ANTES et al. (2007), que, ao avaliarem rosas de corte, cv. 'Vegas', encontraram maior vida em vaso nas hastes condicionadas em $1 \%$ (v/v) Flower ${ }^{\circledR}$. Portanto, a longevidade de muitas flores de corte às soluções preservativas é muito variável entre espécies e cultivares.

Em relação à massa fresca relativa, a maior ocorreu nas hastes submetidas ao tratamento 1,5\% (v/v) Flower Plus ${ }^{\circledR}$, mas não diferiu estatisticamente dos tratamentos Florissant $500^{\circ}, 1 \%$ (v/v) Flower Plus $^{\circledR}$ e $1 \%$ (v/v) Flower ${ }^{\circledR}$.

Já com a absorção de solução, não foram observadas diferenças significativas entre os tratamentos testados, com média de $0,098 \mathrm{~mL} \mathrm{dia}^{-1} \mathrm{~g}^{-1}$ de massa fresca. Esse resultado difere do trabalho de ANTES et al. (2009), em que a absorção de solução foi 
influenciada positivamente com adição de $1 \%(\mathrm{v} / \mathrm{v})$ Flower ${ }^{\circledR}$ para hastes de gérbera de corte cv. 'Patrizia', havendo uma grande diminuição nos valores de água absorvida, a partir do segundo dia após a colheita, sendo maior naqueles tratamentos que não receberam adição do conservante floral. Sob este aspecto, UEYAMA \& ICHIMURA (1998) observaram, com rosas de corte, que a adição de cloro 2-hidroxi-3ioneno (HICP), um composto de amônia quaternária, manteve a absorção de água e suprimiu a redução da condutância hidráulica. Isso sugere que o produto inibiu o bloqueio vascular por microrganismos, pois HICP é conhecido como inibidor do crescimento de actinomicetos.

$\mathrm{O} \mathrm{pH}$, determinado nas soluções de vaso durante o período experimental, apresentou-se com dois patamares distintos, em que os tratamentos Flower $^{\circledR}$ e Flower Plus ${ }^{\circledR}$ estão em uma faixa de $\mathrm{pH}$ que vai de 3,0 a 4,0, enquanto que os tratamentos testemunha e o Florissant $500^{\circ}$ estão na faixa que vai de 5,4 a 6,5. Estas soluções de vaso com $\mathrm{pH}$ mais ácido são mais indicadas para a manutenção de hastes de flores de corte, pois, segundo MERCURIO (2002), não é recomendável utilizar água com $\mathrm{pH}$ alcalino, na faixa entre 7,0 e 7,5 por propiciar maior desenvolvimento bacteriano. Apesar destas diferenças em valores de $\mathrm{pH}$ das soluções de vaso, pode-se inferir que neste caso o $\mathrm{pH}$ não determinou a longevidade das hastes. Esta informação está em conformidade com POMPODAKIS et al. (2004), que relataram que o $\mathrm{pH}$ próximo a 8,0 reduziu a vida em vaso de rosas de corte cv. 'Baccara', por permitir um melhor desenvolvimento de microrganismos na solução de vaso.

As hastes de gérbera de corte nas soluções de vaso apresentaram uma redução no conteúdo de carboidratos totais no tratamento com adição de $1 \%$ (v/v) Flower Plus ${ }^{\circledR}$, quando comparado com as hastes do tratamento testemunha branca (Tabela 1). Contudo, não foram observadas diferenças entre o uso ou não de conservantes durante o período de sete dias em vaso. O comportamento esperado seria o de consumo destas substâncias de reservas, principalmente pelo tratamento testemunha, que não foi adicionado nenhum conservante. Entretanto, observa-se, para as demais características, que o uso de conservantes não conseguiu aumentar a longevidade das hastes, o que pode ter influenciado na característica de consumo das fontes de reserva pela haste.

A quantidade de bactérias no interior das hastes foi significativamente reduzida pela adição dos conservantes florais. JONES \& HILL (1993) afirmam que gérberas são sensíveis a um número relativamente baixo de bactérias, em torno de

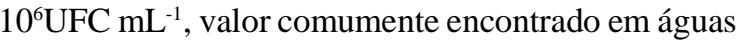
potáveis, três dias após a adição das hastes. Contudo, não foram detectadas diferenças significativas entre as concentrações avaliadas (Tabela 2). Diferente dos resultados obtido por ANTES et al. (2007; 2009), que encontraram menor número de UFC $\mathrm{mL}^{-1}$ com adição de $1 \%$ (v/v) Flower ${ }^{\circledast}$ à solução de vaso.

A metodologia utilizada no presente trabalho, em que se isolam bactérias dos tecidos vegetais de haste, visa a um resultado mais acurado, no sentido de amostrar bactérias que estejam colonizando os vasos condutores e tenham mais chance de realmente ter relação com a obstrução vascular. Contudo, os trabalhos científicos nesta área normalmente isolam as bactérias encontradas nas soluções de vaso. Segundo ZAGORY \& REID (1986), números absolutos de microorganismos em soluções de vaso podem ser menos importantes, para a vida em vaso, do que as espécies, ou cepas de microrganismos presentes.

Tabela 1 - Longevidade, massa fresca relativa, absorção de solução, carboidratos totais em hastes de gérbera de corte, cv. 'Essandre', e pH das soluções de vaso nos diferentes tratamentos. Porto Alegre, Faculdade de Agronomia, UFRGS, 2010

\begin{tabular}{|c|c|c|c|c|c|}
\hline Tratamentos & $\begin{array}{l}\text { Longevidade } \\
\text { (dias) }\end{array}$ & Massa fresca relativa (\%) & $\begin{array}{l}\text { Absorção de solução (mL } \\
\operatorname{dia}^{-1} \mathrm{~g}^{-1} \text { de massa fresca) }\end{array}$ & $\begin{array}{l}\text { Carboidratos } \\
\text { totais }(\%)\end{array}$ & $\begin{array}{l}\mathrm{pH} \text { soluções de } \\
\text { vaso }\end{array}$ \\
\hline Testemunha branca & - & - & - & $56,10 \mathrm{a}$ & - \\
\hline Testemunha & $11,61 \mathrm{ab}$ & $90,24 \mathrm{c}$ & $0,095 \mathrm{a}$ & $47,34 \mathrm{ab}$ & $5,93 \mathrm{~b}$ \\
\hline $1 \%(\mathrm{v} / \mathrm{v})$ Flower ${ }^{\circledR}$ & $11,28 \mathrm{ab}$ & $94,29 \mathrm{abc}$ & $0,105 \mathrm{a}$ & $44,21 \mathrm{ab}$ & $3,71 \mathrm{c}$ \\
\hline $1,5(v / v)$ Flower ${ }^{\circledR}$ & $10,17 \mathrm{bc}$ & $93,31 \mathrm{bc}$ & $0,089 \mathrm{a}$ & $44,91 \mathrm{ab}$ & $3,55 \mathrm{~cd}$ \\
\hline $1 \%(\mathrm{v} / \mathrm{v})$ Flower Plus ${ }^{\circledR}$ & $11,28 \mathrm{ab}$ & $94,78 a b c$ & $0,100 \mathrm{a}$ & $26,41 \mathrm{~b}$ & $3,63 \mathrm{~cd}$ \\
\hline $1,5 \%$ (v/v) Flower Plus ${ }^{\circledR}$ & $8,94 \mathrm{c}$ & $98,65 \mathrm{a}$ & $0,095 \mathrm{a}$ & $41,43 \mathrm{ab}$ & $3,48 \mathrm{~d}$ \\
\hline 1 tablete Florissant ${ }^{\circledR} 500$ & $12,39 \mathrm{a}$ & $95,43 \mathrm{ab}$ & $0,105 \mathrm{a}$ & $46,14 \mathrm{ab}$ & $6,15 \mathrm{a}$ \\
\hline $\mathrm{CV}(\%)$ & 10,17 & 4,07 & 50,9 & 28,7 & 4,72 \\
\hline
\end{tabular}

* Médias seguidas por letras distintas na coluna diferem estatisticamente pelo teste de Duncan $(\mathrm{P}<0,05)$. 
Tabela 2 - Contagem das unidades formadoras de colônias bacterianas (UFC) isoladas de tecido vegetal de hastes de gérberas de corte cv. 'Essandre', submetidas a sete dias em tratamento com conservante floral. Porto Alegre, Faculdade de Agronomia, UFRGS, 2010.

\begin{tabular}{lc}
\hline Tratamento & UFC em $1 \mathrm{~g}$ de tecido vegetal \\
\hline Testemunha & $* 168,01 \mathrm{a}$ \\
$0,75 \%(\mathrm{v} / \mathrm{v})$ Flower $^{\circledR}$ & $23,4 \mathrm{~b}$ \\
$1,5 \%(\mathrm{v} / \mathrm{v})$ Flower $^{\circledR}$ & $25,82 \mathrm{~b}$ \\
$\mathrm{CV}(\%)$ & 20,06 \\
\hline
\end{tabular}

*Médias seguidas por letras distintas na coluna diferem estatisticamente pelo teste de Duncan $(\mathrm{P}<0,05)$.

\section{CONCLUSÃO}

Os conservantes florais testados não aumentam a longevidade pós-colheita de hastes florais de gérbera de corte. O uso de conservante floral reduz o número de bactérias em hastes florais de gérbera de corte.

\section{AGRADECIMENTOS}

Ao Conselho Nacional de Desenvolvimento Científico e Tecnológico (CNPq), pela Bolsa de Mestrado para a primeira autora, sendo este trabalho parte da sua Dissertação de Mestrado.

\section{REFERÊNCIAS}

ALMEIDA, E.F.A. et al. Pós-colheita de copo de leite: efeito de diferentes conservantes comerciais e armazenamento a frio. Ciência e Agrotecnologia, v.32, p.1189-1194, 2008. Disponível em: <http://www.scielo.br/scielo.php?script=sci_arttext\&pid $=\mathrm{S} 1413-70542008000400023>$. Acesso em: 15 jun. 2013. doi: 10.1590/S1413-70542008000400023.

ALMEIDA, E.F.A. et al. Diferentes conservantes comerciais e condições de armazenamento na pós-colheita de rosas. Revista Ceres, v.56, p.193-198, 2009. Disponível em: <http://www.ceres.ufv. br/ceres/revistas/V56N002P51209.pdf>. Acesso em: 26 maio, 2012.

ANTES, R.B. et al. Bloqueio vascular em hastes de rosas de corte cv. 'Vegas'. Revista Brasileira de Biociências, v.5, p.471473, 2007. Disponível em: <http://www.lume.ufrgs.br/bitstream/ handle/10183/31078/000643560.pdf?sequence=1>. Acesso em: 15 mar. 2012.

ANTES, R.B. et al. Bloqueio vascular de hastes de gérberas cv. 'Patrizia'. Revista Biotemas, v.22, p.1-7, 2009. Disponível em: <http://www.biotemas.ufsc.br/volumes/pdf/volume222/1a7.pdf>. Acesso em: 25 mar. 2012.
BHATIAA, R. et al. Assessment of clonal fidelity of micropropagated gerbera plants by ISSR markers. Science Horticulture, n.119, p.208-211, 2009.

BUAINAIN, M.A.; BATALHA, M.O. Cadeia produtiva de flores e mel. Brasília: Ministério da Agricultura, Pecuária e Abastecimento, Secretaria de Política Agrícola, Instituto Interamericano de Cooperação para a Agricultura, 2007. 140p. (Boletim Técnico, 9).

CASTRO, A.C.R. et al. Hastes florais de helicônia sob deficiência de macronutrientes. Pesquisa Agropecuária Brasileira, v.42, p.1299-1306, 2007. Disponível em: <http://www.scielo.br/scielo. php?script=sci_arttext\&pid=S0100-204X2007000900012>. Acesso em: 1 jun. 2012. doi: 10.1590/S0100-204X2007000900012.

CURTI, G.L. et al. Longevidade pós-colheita de inflorescências de girassol. In: SEMINÁRIO SISTEMAS DE PRODUÇÃO AGROPECUÁRIA - AGRONOMIA, 3., 2009, Dois Vizinhos, PR. Anais... Dois Vizinhos: Universidade Tecnológica Federal do Paraná, 2009. 754p. p.95-99.

DURIGAN, M.F.B. Fisiologia e conservação pós-colheita de flores cortadas de gérbera. 2009. 147f. Tese (Doutorado em Agronomia) - Curso de Pós-graduação em Agronomia, Universidade Estadual Paulista Julio de Mesquita Filho, SP.

JONES, R.B.; HILL, M. The effect of germicides on the longevity of cut flowers. Journal of the American Society for Horticultural Science, v.118, p.350-354, 1993.

JUNQUEIRA, A.H.; PEETZ, M.S. A floricultura brasileira no contexto da crise econômica e financeira mundial. 2009. Online. Disponível em: <http://www.hortica.com.br/artigos/A_ floricultura_brasileira_no_contexto_da_crise_financeira_ mundial-1.pdf $>$. Acesso em: 2 jun. 2012.

MERCURIO, G. Gérbera cultivation in greenhouse. The Netherlands: Schreurs, 2002. Cap.13, p.173-175.

POMPODAKIS, N.E. et al. Effects of vase solution $\mathrm{pH}$ and abscisic acid on the longevity of cut "Baccara" roses. Journal Horticulturae Science Biotechnology, v.79, p.828-832, 2004.

REID, M.S.; DODGE, L.L. Flowers handlers: sanitation is crucial. Perishables Handling Quarterly Issue, v.92, p.06-07, 1997.

SOUZA, P.V.D. Efeito de concentração de etefon e pressões de pulverização foliar no raleio de frutinhos em tangerineiras (Citrus deliciosa Tenore) cv. 'Montenegrina'. 1990. 139f. Dissertação (Mestrado em Fitotecnia) - Curso de Pós-graduação em Fitotecnia, Universidade Federal do Rio Grande do Sul, RS.

UEYAMA, S.; ICHIMURA, K. Effects of 2-hydroxy-3-ionene chloride polymer on the vase life of cut rose flowers. Postharvest Biology and Technology, v.14, p.65-70, 1998.

ZAGORY, D.; REID, M.S. Role of vase solution microorganisms in the life of cut flowers. Journal of the American Society for Horticultural Science, v.1, p.154-158, 1986. 